\title{
Knowledge About Osteoporosis in Bruneian Women Attending an Orthopaedic Clinic
}

\author{
H Liza, MRCS, H N Darat, MB ChB, K C Pande, MCh (Orth.) \\ Department of Orthopaedics, Raja Isteri Pengiran Anak Salleh Hospital, Brunei Darussalam
}

\begin{abstract}
Knowledge about osteoporosis was assessed using the Osteoporosis Questionnaire (OPQ) in 100 Bruneian women over 40 years of age, attending an Orthopaedic clinic. The mean total OPQ score was 0.92 ( $\mathrm{SD} \pm 3.91$; range -8 to 10 ; maximum possible score 20). We found no impact of menopausal status, family history of osteoporosis and history of fragility fracture on the total score. The sources of knowledge identified were television/radio (37\%), magazines and newspapers (33\%) and doctors (13\%). The study reveals lack of knowledge about osteoporosis in the present sample, and the need for increased involvement of doctors in educating patients about osteoporosis.
\end{abstract}

Key Words:

Osteoporosis, Patient knowledge, patient education, Osteoporosis questionnaire (OPQ)

\section{INTRODUCTION}

Osteoporosis is defined as 'a systemic skeletal disease characterized by low bone mass and micro-architectural deterioration of bone tissue, with consequent increase in bone fragility and susceptibility to fracture risk' ${ }^{1}$. It is estimated that $30 \%$ of postmenopausal women suffer from this disease ${ }^{2}$. Osteoporosis is now recognised as a global health care problem. Fractures are the hallmark of osteoporosis. These commonly affect the distal radius, vertebral bodies and the hips. Patient education forms an important part of the management of osteoporosis.

Patient education is defined as 'a planned combination of learning activities designed to help people with disease or illness, make changes conducive to health' ${ }^{3}$. Education of women has been suggested to increase appropriate evaluation, prevention and treatment of osteoporosis ${ }^{4}$. It is expected that education will result in better health status through changes in health behaviour ${ }^{5}$. Patient education programmes are acknowledged as an effective way of imparting disease-related knowledge to patients ${ }^{6}$. Such programmes have been demonstrated to increase knowledge ${ }^{7.8}$, improve compliance ${ }^{9}$, change behaviour ${ }^{10}$ and decrease levels of a variety of disease symptoms ${ }^{11}$. Results of a multidisciplinary programme involving patient education suggests that participants develop more effective ways of coping, comply more readily with physician recommendations and acquire more knowledge more about osteoporosis $^{12}$.

It is estimated that about $6.1 \%$ of the population in Brunei Darussalam is over 55 years of age. The life expectancy in men is 74.2 years and 77.3 years in women ${ }^{13}$. If this population is considered in addition to patients who have secondary causes of osteoporosis such as endocrine and gastrointestinal disorders and patients with dermatological and respiratory illnesses who are prescribed steroids, the number of patients 'at risk' for osteoporosis would be considerably higher.

The aim of the present study was to assess the knowledge about osteoporosis in Bruneian women using a convenience sample of Bruneian women over 40 years of age, attending an Orthopaedic clinic and also to identify the sources of their knowledge. We hypothesize that menopausal women, those who have sustained a fragility fracture and/or those who have a family member diagnosed with osteoporosis would know about the disease. The study also examined the impact of these factors on knowledge about osteoporosis.

\section{MATERIALS AND METHODS}

In this study, 100 Bruneian women attending the orthopaedic outpatient department either as a patient or with their family members as patients were recruited. Informed consent for participation in the study was obtained from all subjects who met the inclusion criteria. The study had approval of the hospital ethics committee.

Assessment of knowledge about Osteoporosis: Assessment of knowledge about osteoporosis was undertaken using the Osteoporosis Questionnaire (OPQ), a reliable and validated questionnaire for assessment of patient knowledge about osteoporosis ${ }^{14}$. The 20 item OPQ assesses the patient's knowledge in four areas: i) general knowledge (5 questions); ii) risk factors (7 questions); iii) treatment (4 questions); and, iv) consequences of osteoporosis (4 questions). There are four possible responses for each question of which only one is correct. One of these is a 'don't know' option, which has 
Table I: The effect of three different variables on the OPQ score (Mean \pm SD)

\begin{tabular}{|lcccccc|}
\hline Variables & \multicolumn{2}{c}{ Positive } & \multicolumn{2}{c|}{ Negative } & p value \\
& No & Mean \pm SD & No & Mean \pm SD & \\
\hline History of menopause & 59 & $0.86 \pm 3.98$ & 41 & $1.00 \pm 3.85$ & $\mathrm{~ns}$ \\
Family history of osteoporosis & 10 & $0.50 \pm 2.68$ & 90 & $0.97 \pm 4.03$ & $\mathrm{~ns}$ & $\mathrm{~ns}$ \\
History of fragility fracture & 15 & $1.53 \pm 4.32$ & 85 & $0.81 \pm 3.85$ & $\mathrm{~ns}$ \\
\hline
\end{tabular}

Ns = not significant

\begin{tabular}{|lc|}
\hline Source of knowledge & $\%$ \\
\hline Friends & 17 \\
Family members & 7 \\
Doctor & 13 \\
Magazine / Newspaper & 33 \\
TV / Radio & 37 \\
Others & 8 \\
\hline
\end{tabular}

Fig. 1: Sources of patient knowledge about osteoporosis

been included to improve patient compliance and scored 0 points. Each correct response is scored with 1 point and an incorrect response scored -1 . The maximum and minimum score on the OPQ is 20 and -20 respectively. In addition to the multiple choice questions, three open questions were asked relating to the definition of osteoporosis, its consequences and treatment options.

Sources of patient knowledge: Patients were asked to identify their sources of knowledge under six headings: family, friends, family doctor, magazine and newspaper, television and radio and other sources.

An additional questionnaire was administered to identify risk factors for osteoporosis such as menopausal status, history of fractures, and family history of osteoporosis. This also allowed us to examine the impact of these factors on the knowledge about osteoporosis within the sample. In order to improve participation by subjects, the OPQ and additional questionnaire were translated into Malay. It was reviewed by 10 Malay individuals for comprehensibility prior to its use in the study.

The statistical analysis was performed utilizing SPSS for Windows, Version 10. The total score for the OPQ is expressed as mean $\pm \mathrm{SD}$ (Standard Deviation) and was confirmed to have a normal distribution. The $t$ test was used to study the differences in total scores for different groups of variables. A p value $<0.05$ was considered significant.

\section{RESULTS}

The average age of the sample was 53.9 years $(\mathrm{SD} \pm 7.4$ years; range 40-77 years). The mean total score for the OPQ was 0.92 ( $\mathrm{SD} \pm 3.91$ ). The minimum score was -8 and the maximum score was 10 . The effect of three different variables on the OPQ score is given in Table I. We found no impact of menopausal status, family history of osteoporosis and history of fragility fracture on the total score. The most common source of knowledge was television and radio (37\%) followed by magazines and newspapers (33\%). In response to open questions, only $43 \%$ of subjects provided a correct response for definition of osteoporosis and $24 \%$ for consequences while $41 \%$ were aware of some treatment options (Figure 1).

\section{DISCUSSION}

The present study demonstrates deficiencies in knowledge about osteoporosis and also identifies multiple sources of patient knowledge in the sample.

\section{Knowledge about Osteoporosis}

In agreement with the present study where $43 \%$ of subjects knew the definition of osteoporosis, satisfactory knowledge about the definition of osteoporosis has been demonstrated, mainly in the elderly population, ${ }^{15-19}$ but a large number of woman confused osteoporosis with arthritis ${ }^{17}$. Ungan and Tumer ${ }^{19}$ found that awareness about osteoporosis was particularly low in the areas of risk factors and consequences. The findings of the present study regarding poor knowledge of consequences $(23 \%)$ are consistent with those of Ungan and Tumer.

Magnus et al ${ }^{15}$ surveyed a random sample of 1514 Norwegian women and men aged 16-79 years, and found a high degree of general knowledge of osteoporosis and its consequences in the general population. A higher level of education and knowing someone with osteoporosis was associated with increased awareness. Using the OPQ, Vytrisalova et $a l^{20}$ reported higher knowledge scores in subjects who were diagnosed with osteoporosis and receiving treatment. In the present study, we found no effect of positive family history or history of fragility fracture on the level of knowledge about osteoporosis.

The OPQ was used in a sample of 50 English women over 50 years of age. The total mean score was found to be 8.5 $(\mathrm{SD} \pm 5.4)$ with a range of -2 to $17^{21}$. In another study conducted in India, a total of 73 female staff members (average age 44.7 years) of a teaching institute completed the $\mathrm{OPQ}$. The mean $\pm \mathrm{SD}$ of total score for the sample was 4.1 ( $\mathrm{SD} \pm 4.1$; range -8 to 15 ). There was no influence of age, menopausal status, previous history of fracture and family 
history of osteoporosis on the level of knowledge ${ }^{22}$. The wide variation in the total score in the present study, and also in the Indian and English women may reflect an individual's desire to know more about the condition or their access to such information. It could be a result of differing social and educational backgrounds of the population.

\section{Sources of Knowledge}

Several sources of patient knowledge have been identified in the present study with media $(70 \%)$ being the commonest source. Similar findings were noted in the two previous studies using the OPQ with $86 \%$ and $74 \%$ of subjects identifying media as the source of their knowledge ${ }^{21,22}$. Doctors were identified as the source of knowledge about osteoporosis by $13 \%$ in the present study in contrast to $50 \%$ and $25 \%$ of subjects in the previous studies ${ }^{21,22}$.

$\mathrm{Pal}^{23}$ reported results of a questionnaire survey of patients with reference to the advice they received after sustaining a fragility fracture. Before sustaining a fracture, $42 \%$ of patients were aware of osteoporosis and its risk, with the source of information identified as mainly the media (70.5\%) and only occasionally from their doctors (29.5\%). In another study, television, newspapers and friends were identified as the main source of information with physicians ranking fifth as a source of information ${ }^{24}$.

Juby and Davis ${ }^{24}$ have shown that the information available in the media may be variable and inaccurate. Molnar et $a l^{25}$ assessed the quality of information available through the medical advice columns of newspapers in Canada, and found that inappropriate information was provided in $50 \%$ of the articles, and further that advice given may have been dangerous and potentially life threatening in $28 \%$ of the columns. In view of those of Ungan and Tumer reports, media being the most common source of knowledge in the present as well as other studies is a cause of concern.

Based on the results of present study, with particular reference to Brunei, it is recommended that more health care personnel should be involved in educating 'at risk' populations about osteoporosis. Awareness about osteoporosis can be raised through doctors writing in the common media, presenting lectures for the public and through posters in waiting area of clinics and outreach centres. A validated tool like the OPQ should then be used to assess the efficacy of the above interventions.

A limitation of the study was that the influence of educational level on the OPQ score could not be determined due to the wide age range of subjects and varied educational levels of study participants. It is possible that the educational level may not have a significant impact on the knowledge levels as such a result was seen in a previous study by Pande et al that used the $\mathrm{OPQ}^{22}$. In this study, subjects with postgraduate degrees, employed as teaching staff in a college were noted to have a very low OPQ score.

\section{CONCLUSION}

The present study has identified deficiencies in knowledge about osteoporosis in Bruneian women attending an orthopaedic clinic. With the maximum possible score 20, the mean total score of the sample was only 0.92. Health authorities and physicians should be involved in patient education efforts in order to improve knowledge as well as maintain the quality and reliability of information provided regarding osteoporosis. 


\section{REFERENCES}

1. Consensus Development Conference V, 1993: Diagnosis, prophylaxis, and treatment of osteoporosis. Am J Med 1993; 94 : 646-50.

2. Kanis JA, Melton LJ, Christianson C, Johnston CC, Khaltaev N. The diagnosis of osteoporosis. J Bone Miner Res 1994; 9: 1137-41.

3. Green LW, Krueler M, Partridge KB, Deeds SG. Health education planning: a diagnostic approach. Palo Alto, Mayfield, 1979.

4. Kasper MJ, Peterson MG, Allegrante JP, Galsworthy TD, Gutin B. Knowledge, beliefs, and behaviour among women concerning the prevention of osteoporosis. Arch Fam Med 1994; 3: 696-702.

5. Lorig K, Konkol L, Gonzalez V. Arthritis patient education: a review of literature. Patient Educ Counselling 1987; 10: $207-52$.

6. Edworthy SM, Devins GM, Watson MM. The arthritis knowledge questionnaire: a test for measuring patient knowledge of arthritis and its self-management. Arthritis Rheum 1995; 38: 590-600.

7. Potts MK, Brandt KD. Analysis of education support groups for patients with rheumatoid arthritis. Patients Couns Health Educ 1983; 4:161-6.

8. Lindorth A, Bauman A, Barnes C, McCredie M, Brooks PM. A controlled evaluation of arthritis education. Br J Rheumatol 1989; 28: 7-12.

9. Gross M, Brandt KD. Educational support groups for patients with ankylosing spondilytis: a preliminary report. Patient Counsell Health Educ 1981; 3: 6-12.

10. Cohen JL, Sauter S, Devellis R, Devellis B. Evaluation of arthritis self-management courses led by lay persons and by professionals. Arthritis Rheum 1986; 29: 388-93.

11. Lehew JK. The use of hypnosis in the treatment of musculoskeletal disorders. Am J Clin Hypn 1970; 13: 131-4.

12. Riordan ME, Bales CW, Drezner MK. A preventative and therapeutic program for osteoporosis: A multi-faceted approach to care. Health Values 1987; 11:51-6.

13. Statistics Unit, Research and Development Section, Department of Policy and Planning, Ministry of Health, Brunei Darussalam. Health Information Booklet 2005. Page 2-4.

14. Pande KC, de Takats D, Edwards V, Slade P, Kanis J. Development of a questionnaire (OPQ) to assess patient's knowledge about osteoporosis. Maturitas 2000; 237: 75-81.

15. Magnus JH, Joakimsen RM, Berntsen GK, Tollan A, Søogaard AJ. What do Norwegian women and men know about osteoporosis? Osteoporos Int 1996; 6: 31-6.

16. Phillipov G, Phillips PJ, Leach G, Taylor AW. Public perceptions and self-reported prevalence of osteoporosis in South Australia. Osteoporos Int 1998; 8: 552-6.

17. Satterfield T, Johnson SM, Slovic P, Neil N, Schein JR. Perceived risks and reported behaviours associated with osteoporosis and its treatment. Women Health 2000; 31: 21-40.

18. Kasper MJ, Peterson MG, Allegrante JP. The need for comprehensive educational osteoporosis prevention programs for young women: results from a second osteoporosis prevention survey. Arthritis Rheum 2001; 45: 28-34.

19. Ungan M, Tumer M. Turkish women's knowledge of osteoporosis. Fam Pract 2001; 18: 199-203.

20. Vytrisalova M, Kubena A, Vlcek J, Palicka V, Hala T, Pavelka K. Knowledge of osteoporosis correlated with hormone therapy use and health status. Maturitas 2007; 20: 21-9.

21. Pande KC, de Takats D, McCloskey EV, Edwards V, Slade P, Kanis J. What do patients know about osteoporosis? Proceedings of the 67th Annual Meeting of American Academy of Orthopaedic Surgeons 2000. Orlando, FL: American Academy of Orthopaedic Surgeons.

22. Pande K, Pande S, Tripathi S, Kanoi R, Thakur A, Patle S. Poor knowledge about osteoporosis in learned Indian women. J Assoc Physicians India 2005; 53: 433-6.

23. Pal B. Questionnaire survey of advice given to patients with fracture. BMJ 1999; 318(7182): 5 00-1.

24. Juby AG, Davis P. A prospective evaluation of the awareness, knowledge, risk factors and current treatment of osteoporosis in a cohort of elderly subjects. Osteoporos Int 2001; 12: 617-22.

25. Molnar FJ, Man-Son-Hing M, Dalziel WB, Mitchell SL, Power BE, Byszewski AM, St John P. Assessing the quality of newspaper medical advice columns for elderly readers. Can Med Assoc J 1999; 161: 393-5. 